\title{
Activated T-Cells Inhibit Neurogenesis by Releasing Granzyme B: Rescue by Kv1.3 Blockers
}

\author{
Tongguang Wang, Myoung-Hwa Lee, Tory Johnson, Rameeza Allie, Lina Hu, Peter A. Calabresi, and Avindra Nath \\ Department of Neurology, The Johns Hopkins University, Baltimore, Maryland 21287
}

There is a great need for pharmacological approaches to enhance neural progenitor cell (NPC) function particularly in neuroinflammatory diseases with failed neuroregeneration. In diseases such as multiple sclerosis and stroke, T-cell infiltration occurs in periventricular zones where NPCs are located and is associated with irreversible neuronal loss. We studied the effect of T-cell activation on NPC functions. NPC proliferation and neuronal differentiation were impaired by granzyme B ( GrB) released by the T-cells. GrB mediated its effects by the activation of a Gi-protein-coupled receptor leading to decreased intracellular levels of cAMP and subsequent expression of the voltagedependent potassium channel, Kv1.3. Importantly, blocking channel activity with margatoxin or blocking its expression reversed the inhibitory effects of GrB on NPCs. We have thus identified a novel pathway in neurogenesis. The increased expression of Kv1.3 in pathological conditions makes it a novel target for promoting neurorestoration.

\section{Introduction}

The incidence of neurodegenerative disorders continues to rise. However, currently available neuroprotective therapies have uniformly shown either no or at best marginal benefit in these diseases; hence the focus is shifting toward the development of neurorestorative therapies. The possibility that endogenous or transplanted neural progenitor cells (NPCs) can replace lost brain tissue has raised enormous hope among the public and the scientific community. NPCs are present in the adult brain and they retain the ability to proliferate and differentiate into neurons and glial cells (Arvidsson et al., 2002). Their therapeutic potential in neurodegenerative disorders is also being explored (Ikeda et al., 2005; Hayashi et al., 2006). Therefore, any damage to NPCs may result in the inability to replace lost or injured neurons and could be a contributing factor to the brain atrophy. It is thus critical to understand the subcellular environment in which these cells reside.

T-cells play an important role in inflammatory-associated neurodegenerative diseases. It was recently demonstrated that blockade of the infiltration of T-cells into the brain reduced infarct/reperfusion-induced brain infarction and accompanying neurological deficits (Shichita et al., 2009). In neuroinflammatory diseases such as multiple sclerosis, infiltrates of activated T-cells are present in the periventricular zones where the NPCs are localized (Nait-Oumesmar et al., 2007; Matsushita et al., 2008). Multiple sclerosis is also accompanied with progressive brain atrophy, suggesting a failure of the regenerative process

Received Jan. 20, 2010; accepted Feb. 22, 2010.

This work was supported by the Maryland Stem Cell Fund, National Multiple Sclerosis Society Grant TR3760-A-3, and National Institutes of Health Grants R01-NS056884 and R01-NS41435. We thank Dr. George Chandy for helpfu comments.

Correspondence should be addressed to Dr. Avindra Nath, Department of Neurology, Pathology Building, Room 509, 600 North Wolfe Street, Baltimore, MD 21287. E-mail: anath1@jhmi.edu.

DOI:10.1523/JNEUROSCI.0311-10.2010

Copyright $\odot 2010$ the authors $\quad 0270-6474 / 10 / 305020-08 \$ 15.00 / 0$
(Chard et al., 2004; Furby et al., 2008). Despite the recognition that, if NPCs were to be implanted in patients with multiple sclerosis, they would be subjected to an inflammatory environment, there seems to be great enthusiasm in exploring this as a therapeutic option in these patients (Duncan et al., 2008). Although some studies have shown that NPCs can attenuate T-cell activation through its antiinflammatory effect (Pluchino et al., 2005; Uccelli et al., 2006), it remains unknown whether activated T-cells may affect NPC function.

In multiple sclerosis, $\mathrm{CD} 8{ }^{+} \mathrm{T}$-cells predominate in the inflammatory infiltrate in both acute and chronic lesions. In these patients, clonal expansion of these cells may occur and they demonstrate the presence of cytotoxic granules (Friese and Fugger, 2005; Goverman et al., 2005; Friese et al., 2008). Other neuroinflammatory diseases such as Rasmussen's syndrome and CNSimmune reconstitution syndrome associated with human immunodeficiency virus infection are also associated with infiltration of $\mathrm{CD} 8{ }^{+} \mathrm{T}$-cells and brain atrophy but have not been as well studied (Venkataramana et al., 2006; Schwab et al., 2009). Hence we sought to determine whether activated T-cells could impact NPC function. We observed that granzyme B (GrB) was a key factor that inhibited NPC proliferation and neuronal differentiation. The underlying mechanisms involve activation of pertussis toxin (PTX)-sensitive Gi-coupled receptors and increased expression of voltage-dependent potassium channel Kv1.3 in NPCs. Since there is increased expression of Kv1.3 in activated T-cells as well and antagonists of this receptor can block T-cell activation ( $\mathrm{Hu}$ et al., 2007), Kv1.3 antagonists may play a dual role by controlling T-cell activation and enhancing NPC function.

\section{Materials and Methods}

Cell cultures. Cell culture medium and supplements were purchased from Invitrogen if not specifically described. Human NPCs were cultured from human fetal brain specimens of 7-8 weeks of gestation in accordance with National Institutes of Health $(\mathrm{NIH})$ guidelines and following approval by the Institutional Review Board at The Johns Hopkins Uni- 
versity. The tissues were then triturated after removing meninges and blood vessels. After centrifugation at $1000 \mathrm{rpm}$, cells were resuspended in DMEM/F12 media [containing $8 \mathrm{~mm}$ glucose, $1 \times \mathrm{N} 2$ supplement, $1 \%$ antibiotics, $0.1 \%$ albumin (Sigma-Aldrich), human fibroblast growth factor- $\beta$ (hFGFb) $(20 \mathrm{ng} / \mathrm{ml}$ ), and human epidermal growth factor (hEGF) $(20 \mathrm{ng} / \mathrm{ml})]$ and plated onto poly-D-lysine (Sigma-Aldrich)coated T $25 \mathrm{~cm}^{2}$ tissue culture flasks. When cell cultures reached $60 \%$ confluence, they were subcultured by treatment with $0.0125 \%$ trypsin (Sigma-Aldrich) and plated at a density of $2 \times 10^{4}$ cells $/ \mathrm{ml}$ onto poly-Dlysine-coated 96 -well plates or coverslips in 24-well plates. Medium was replaced every other day. NPC cultures were ready for experiments $4-5 \mathrm{~d}$ after replating and $>98 \%$ of the cells expressed the neural stem cell marker nestin, whereas $<1 \%$ of the cells expressed glial fibrillary acidic protein (GFAP) (a marker for astrocyte) or $\beta$-III-tubulin (a neuronal cell marker) as determined by immunocytochemistry. Cell proliferation was assessed by incubating the cells with bromodeoxyuridine (BrdU) labeling reagent (1:100; Zymed) for $6 \mathrm{~h}$ followed by immunostaining for BrdU. When subjected to differentiation media by replacing hEGF- and hFGFb-containing medium with fresh medium containing $1 \%$ of FBS (Gemini), the NPCs were capable of differentiating into neurons (10$50 \%$ ) and astrocytes (50-90\%) after 4-7 d (supplemental Fig. 1, available at www.jneurosci.org as supplemental material).

CD8 ${ }^{+}$T-cells were isolated from peripheral blood mononuclear cells of healthy human adult donors. $\mathrm{CD} 8^{+} \mathrm{T}$-cells were isolated by negative selection using MACS beads (Miltenyi Biotec) and then incubated at $37^{\circ} \mathrm{C}$ in Iscove's modified Dulbecco's medium with $5 \%$ pooled human serum and activated by placing on plates coated with $1 \mu \mathrm{g} / \mathrm{ml}$ anti-CD3 and $1 \mu \mathrm{g} / \mathrm{ml}$ anti-CD28 for $72 \mathrm{~h}$ in culture. Culture supernatants (sups) were then collected and incubated (1:20 dilution) with NPCs. To deplete GrB from T-cell sups, the sups were incubated 1:1 with preswollen protein G-Sepharose (GE Healthcare) for $2 \mathrm{~h}$ at $4^{\circ} \mathrm{C}$, a step taken to eliminate proteins in the lysate that may bind nonspecifically to the protein G. The sups were subsequently spun and incubated at $4^{\circ} \mathrm{C}$ overnight on a rotary table with a monoclonal anti-GrB (Millipore) or an isotype-matched mouse IgG2a-negative control antibody (Millipore). This mix was then incubated for $2 \mathrm{~h}$ with protein $\mathrm{G}$-Sepharose and filtered through a column. The flow through was used to treat NPC cultures. All incubations (antibody and protein $\mathrm{G}$ ) were performed on a rotary table at $4^{\circ} \mathrm{C}$, and all centrifugations were performed using a desktop Eppendorf centrifuge at $4^{\circ} \mathrm{C}$ for $5 \mathrm{~min}$ at maximum speed $(9000 \times \mathrm{g})$.

Immunocytochemistry. Cells were fixed in $4 \%$ paraformaldehyde and permeabilized by incubation in $0.5 \%$ Triton X-100 in PBS (PBS-T) for 20 min. For BrdU staining, the cells were also denatured in $2 \mathrm{~N} \mathrm{HCl}$ at $37^{\circ} \mathrm{C}$ for $30 \mathrm{~min}$ and rinsed twice in $0.1 \mathrm{~m}$ sodium borate, $\mathrm{pH} 8.5$, followed by the process described above. Cells were immunostained using monoclonal anti-BrdU (1:1000; Sigma-Aldrich), monoclonal anti- $\beta$-III-tubulin (1:1000; Promega), rabbit anti-GFAP (1:1000; Sigma-Aldrich), rabbit anti-active caspase-3 (1:1000; Sigma-Aldrich), monoclonal anti-nestin (1:1000; gift from Dr. Eugene Major, NIH, Bethesda, MD), monoclonal anti-CD68 (1:100; Invitrogen), rabbit anti-Oct4 (1:500; Cemines Biosystems), followed by corresponding secondary antibodies (anti-rabbit Alexa Fluor 488, 1:400; anti-mouse Alexa Fluor 597, 1:400; Invitrogen) and 4',6-diamidino-2-phenylindole (DAPI) nuclear staining. Images were acquired on a Zeiss LSM 510 META multiphoton confocal system (Carl Zeiss).

GrB levels. GrB levels were measured in tissue culture supernatants and in CSF by ELISA according to the manufacturer's instructions (Cell Sciences). Briefly, peripheral blood mononuclear cells were obtained from healthy adult donors. $\mathrm{CD} 8{ }^{+} \mathrm{T}$-cells were isolated by a standard protocol using a bead depletion method (Miltenyi Biotec). A total of $2 \times 10^{5}$ cells was seeded per well in a 96-well round-bottom plate. Cells were then stimulated with anti-CD3 and anti-CD28 Dynabeads according to the manufacturer's protocol omitting recombinant IL-2 (Invitrogen) for $72 \mathrm{~h}$ at $37^{\circ} \mathrm{C}$ and $5 \%$ carbon dioxide. Cell supernatants were collected and stored at $-20^{\circ} \mathrm{C}$ until analyzed for $\mathrm{GrB}$ levels. CSF samples were obtained from The Johns Hopkins CSF repository following approval by the Institutional Review Board. Control samples were from 10 patients with headaches caused by pseudotumor cerebri. Another 10 patients had clinically definite remitting relapsing multiple sclerosis.
A

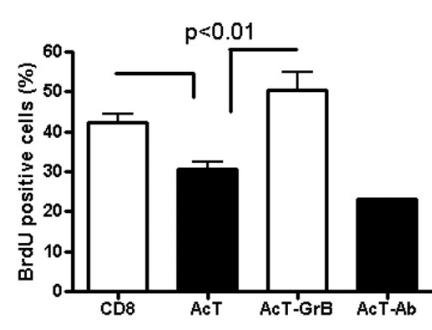

$\mathrm{Bi}$

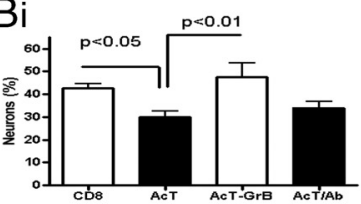

$\mathrm{Bii}$

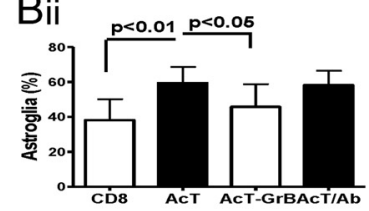

C

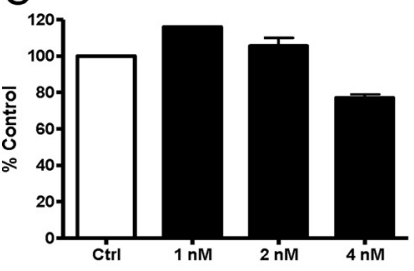

D $\quad p<0.05$

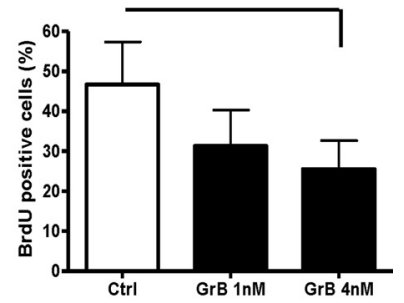

E

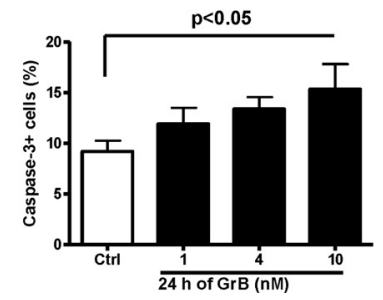

$\mathrm{F}$

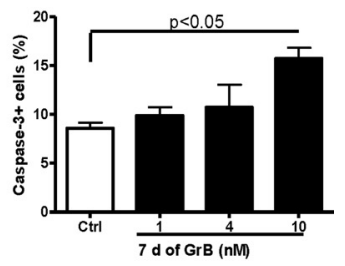

Figure 1. GrB released from activated CD8 ${ }^{+} \mathrm{T}$-cells inhibits NPC neurogenesis. $A$, Human primary NPC cultures on poly-D-lysine-coated coverslips were treated with sups (1:20 dilution) from nonactivated $C D 8{ }^{+}$T-cells (CD8), activated $C D 8{ }^{+} \mathrm{T}$-cells (AcT), and AcT immunodepleted with anti-GrB (ACT-GrB) or control antibody (ACT-Ab). After $24 \mathrm{~h}$ of treatment, cell proliferation was determined by BrdU incorporation. Sups from activated CD8 ${ }^{+} \mathrm{T}$-cells significantly decreased the number of BrdU-positive cells, whereas immunodepletion of GrB from the sups significantly attenuated this effect. $\boldsymbol{B}$, Neuronal and astroglial differentiation were determined $4-7 \mathrm{~d}$ later by immunostaining with anti- $\beta$-III-tubulin and GFAP antibodies. $\beta$-III-tubulinpositive neurons (Bi) and GFAP-positive astroglia (Bii) were counted in each well. Cells in nine preassigned fields ( $\sim 200$ cells/field) were counted on each coverslip, and three coverslips were counted in every group. The cell numbers are expressed as percentage of total cells. C, NPCs were cultured on poly-D-lysine-precoated 96-well plates and treated with recombinant GrB (1- $4 \mathrm{~nm})$ for $24 \mathrm{~h}$. Untreated cells were used as control. CellQuanti-Blue dye was added in each well for 30 $\mathrm{min}$. Fluorescence was then detected using a plate reader at $590 \mathrm{~nm}$. No significant effect of GrB was noted. $\boldsymbol{D}, \mathrm{NPC}$ cultures on poly-D-lysine-precoated coverslips were treated with recombinant $\mathrm{GrB}(1-4 \mathrm{~nm})$ for $24 \mathrm{~h}$. Cell proliferation was determined by BrdU incorporation as described in $\boldsymbol{A}$. Significant decrease in NPC proliferation was noted with $4 \mathrm{~nm} \mathrm{GrB}$. Caspase-3-positive apoptotic cells were also calculated in NPC cultures receiving GrB treatment after $24 \mathrm{~h}(\boldsymbol{E})$ or $7 \mathrm{~d}(\boldsymbol{F})$ using immunostaining. Data in each panel represent mean \pm SEM from at least three different experiments.

Treatment with T-cell sups and GrB. To monitor the effect of NPC proliferation, cultures were treated with T-cell sups (1:20) and GrB (4 nM; Calbiochem) for $24 \mathrm{~h}$ in proliferating media and then analyzed as described above. To determine effects on neuronal differentiation, the NPC cultures were similarly treated in differentiating media for $4-7 \mathrm{~d}$ and the differentiating cell types were quantified by immunostaining. $\beta$-Tubulin-positive neurons and total DAPI-positive cells were counted in nine predetermined fields in each of the two coverslips in every treatment. The percentage of $\beta$-tubulin-positive cells was used as an index for neurogenesis.

Cytotoxicity assays. Cytotoxicity was evaluated by using CellQuantiBlue Cell Viability Assay kit (BioAssay Systems) according to the manufacturer's instructions. Briefly, NPCs were cultured in maintaining media in 96-well plates and used for experiments at $\sim 60 \%$ confluence. After adding GrB (1-4 nM), the cells were cultured for $24 \mathrm{~h}$. CellQuanti- 


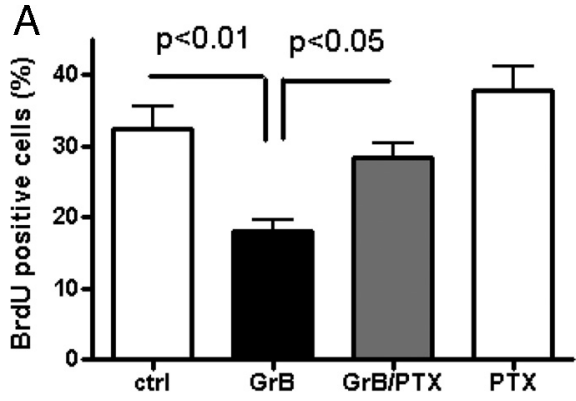

B

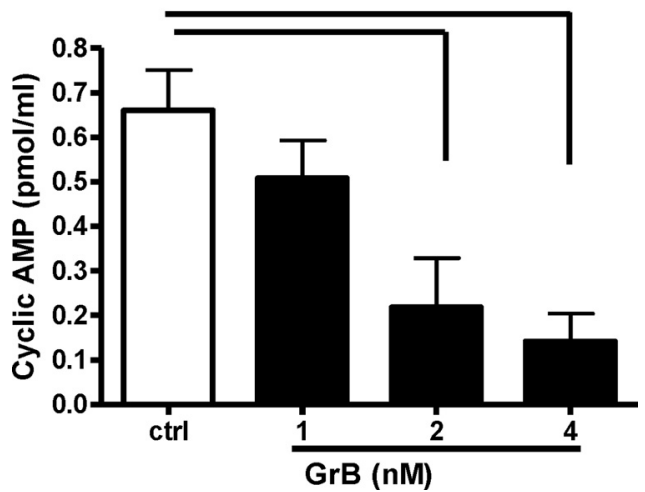

Figure 2. GrB acts on NPCs via Gi $\alpha /$ Go-coupled receptor. $A, N P C$ cultures were treated with $\mathrm{GrB}(4 \mathrm{~nm})$ and PTX (100 ng/ml) for $24 \mathrm{~h}$. Cell proliferation was determined by BrdU incorporation. PTX protected against GrB-induced effects on NPC proliferation. $\boldsymbol{B}$, NPC cultures in 24-well plates were treated with $\mathrm{GrB}(0-4 \mathrm{~nm})$ for $15 \mathrm{~min}$. CAMP levels were detected in the cell lysates by ELISA. Data represent mean \pm SEM from three independent experiments.

Blue solution ( $10 \mu \mathrm{l} /$ well) was added and the cells were incubated for $1 \mathrm{~h}$. The fluorescence was quantified at an excitation wavelength of $530 \mathrm{~nm}$ and emission wavelength of $590 \mathrm{~nm}$ using a fluorescence plate reader. Apoptosis was also evaluated by calculating the percentage of active caspase-3-positive NPCs after $24 \mathrm{~h}$ or $7 \mathrm{~d}$ of GrB (1-10 nM) treatment by using immunostaining.

cAMP assay. NPCs were seeded in 24-well plates until the cells reached $90 \%$ confluence. Cultures were then treated with GrB (1-4 nM) in maintaining media for $30 \mathrm{~min}$. After removing the media, the cells were treated with $100 \mu \mathrm{l}$ of $0.1 \mathrm{M} \mathrm{HCl}$ and $1 \%$ Triton X-100 for $10 \mathrm{~min}$ to achieve cell lysis. The lysates were centrifuged at $600 \times g$ for $10 \mathrm{~min}$ at room temperature, and the supernatants were used for the cAMP assay using a competitive ELISA kit (Endogen) according to the manufacturer's directions.

Kv1.3 expression on NPCs. Kv1.3 expression was determined by quantitative real-time PCR. NPCs were treated with GrB for $3 \mathrm{~h}$ and total RNA was extracted using QIAGEN RNeasy mini kit (QIAGEN). The RNA samples were treated with DNase I (Invitrogen) for $15 \mathrm{~min}$ and then used for first-strand cDNA synthesis using SuperScript III First-Strand cDNA kit (Invitrogen). Real-time PCR was performed using ABI Prism 7000 Sequence Detection System (Applied Biosystems) according to the manufacturer's instructions, using a human Kv1.3 detection kit (SAbioscience). Glyceraldehyde-3-phosphate dehydrogenase (GAPDH) was used as an internal control. The standard curves were plotted for both Kv1.3 and GAPDH in each plate using serially diluted preset samples. The ratio of Kv1.3/GAPDH for every sample was first calculated, and results were expressed as fold changes compared with control. Kv1.3 expression was also monitored in NPCs by immunocytochemistry and Western blot using anti-Kv1.3 polyclonal serum (1:100; Alomone Labs). Dual staining for nestin was also performed in immunocytochemistry as described above.

Inhibition of Kv1.3 expression with short interfering RNA. Human NPCs were maintained in proliferating medium in 24 -well plates for $\sim 1$ week at which time they reached $\sim 60 \%$ confluence and were used for trans-
A

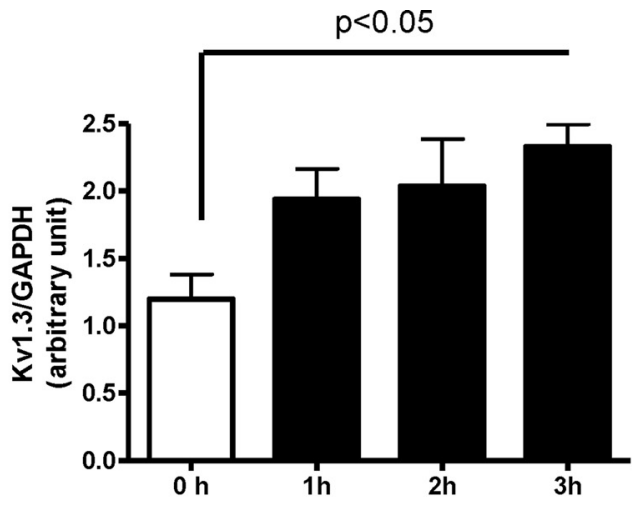

B
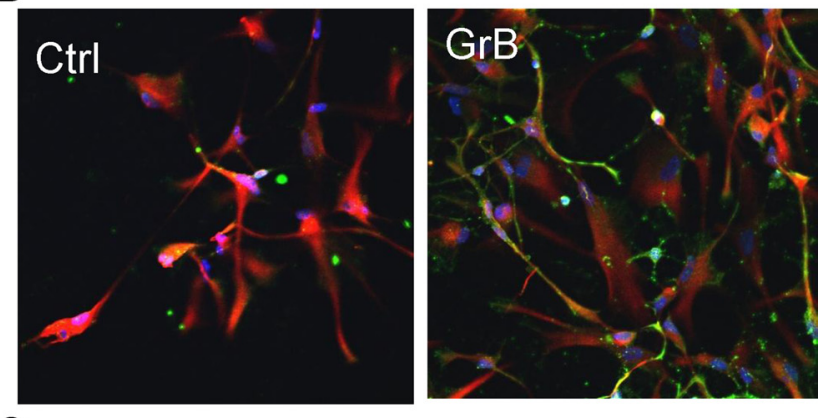

C

$\mathrm{Kv} 1.3$

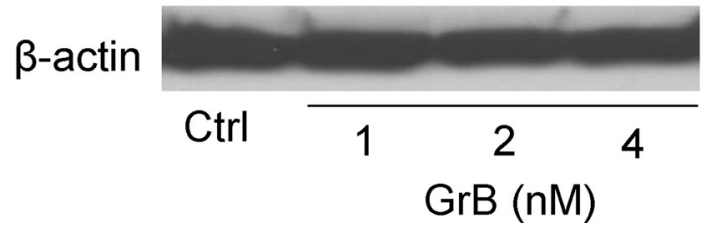

Figure 3. Kv1.3 expression in GrB-treated NPCs. A, Kv1.3 gene expression was detected using real-time PCR in NPC cultures treated with GrB (4 nM) for 1-3 h. GAPDH was used as an internal control. Dose-dependent increase in Kv1.3 mRNA expression was noted. Data represent mean \pm SEM from four independent experiments. $B, N P C$ cultures were treated with $\mathrm{GrB}(4 \mathrm{~nm})$ for $24 \mathrm{~h}$ and immunostained with antibodies to Kv1.3 and nestin (red, nestin; green, Kv1.3). C, NPC cultures were treated with GrB (1-4 nм) for $24 \mathrm{~h}$, and the cell lysates were collected for detecting Kv1.3 production using Western blot analysis. This shows a dose-dependent increase in Kv1.3 detection.

fection of short interfering RNA (siRNA). Kv1.3 siRNA was chemically synthesized, stabilized, and fluorescent labeled by Dharmacon. Briefly, 1 $\mu \mathrm{l}$ of transfectamine (Invitrogen) was added to Opti-MEM I reduced serum medium to a final volume of $50 \mu \mathrm{l}$. A volume of $0.2 \mu \mathrm{l}$ of siRNA was added to Opti-MEM I to a final volume of $50 \mu \mathrm{l}$ and incubated for 5 min. The siRNA and transfectamine solutions were combined and mixed by gently pipetting and incubated at room temperature for $20 \mathrm{~min}$. Cells were washed with Opti-MEM I, and $400 \mu \mathrm{l}$ of fresh Opti-MEM I was added to each well. The transfection agent/siRNA complex was added dropwise onto the cells and incubated for $24 \mathrm{~h}$ at $37^{\circ} \mathrm{C}$. Select wells were treated with $4 \mathrm{~nm}$ GrB plus 1\% serum in DMEM/F12. Gene expression was studied by real-time PCR, and cell proliferation and differentiation were determined as described above.

Animals and procedures. Eight-week-old female Sprague Dawley rats purchased from Charles River Laboratories were randomly divided into three groups for stereotaxic injection in the hippocampal dentate gyrus (DG). Group I $(n=6)$ received $1 \mu \mathrm{g}$ of recombinant GrB in $1 \mu \mathrm{l}$ of PBS. Group II $(n=5)$ received 10 ng of margatoxin (MgTX) (Alomone Labs) and $1 \mu \mathrm{g}$ of recombinant GrB together in $1 \mu \mathrm{l}$ of PBS. Group III $(n=7)$ received vehicle as a control. After $7 \mathrm{~d}$, the rats received a BrdU (100 $\mathrm{mg} / \mathrm{kg}$; Sigma-Aldrich) intraperitoneal injection $2 \mathrm{~h}$ before being killed. The brains were collected and postfixed in $4 \%$ paraformaldehyde for $24 \mathrm{~h}$ 
A
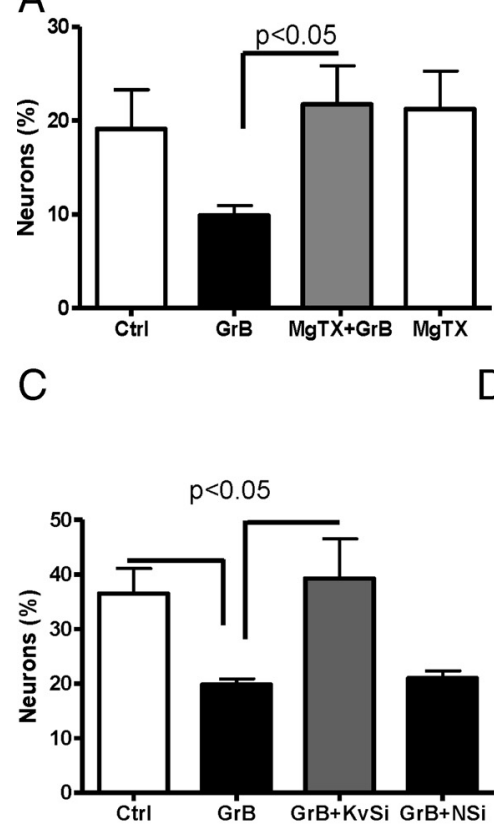

C

Ctrl
B

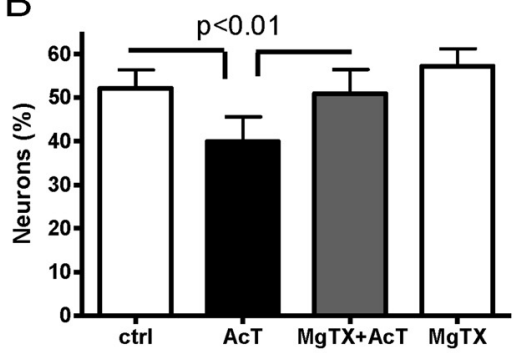

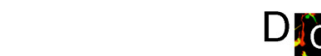
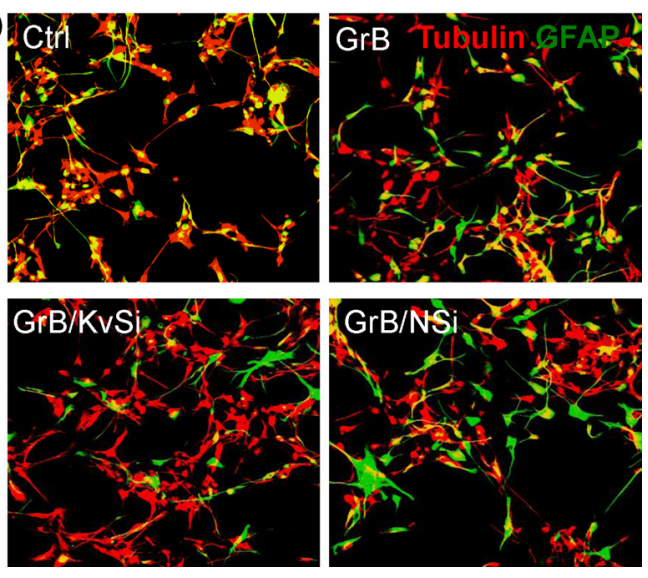

Figure 4. Kv1.3 mediates effect of GrB on NPC neurogenesis. To monitor NPC neurogenesis, NPC cultures were cultured in differentiating media for 4-7 d. Cells were immunostained with anti- $\beta$-III-tubulin antibody (red) and anti-GFAP antiserum (green). $\beta$-III-Tubulin-positive neurons were counted in each well and the cell numbers were expressed as percentage of total cells. Cells in five preassigned fields ( $\sim 200$ cells/field) were counted on each coverslip, and three coverslips were counted in every group. Data represent mean \pm SEM from three experiments. A, Kv1.3-selective blocker MgTX (10 nM) prevented the effects of GrB $(4 \mathrm{~nm})$ on NPC neurogenesis. $\boldsymbol{B}, \mathrm{MgTX}$ also attenuated the effect of supernatants from activated T-cells (AC-T) on NPC neurogenesis. C, Transfection of Kv1.3 siRNA (25 nm final concentration) but not nonspecific control (NSi) into NPCs blocked the effects of GrB (4 nM) on NPC neurogenesis. Error bars indicate SEM. D, Representative photomicrographs immunostaining for $\beta$-III-tubulin.

\section{Results}

Activated T-cells inhibited NPC neurogenesis through release of $\mathrm{GrB}$ The effect of activated T-cells on neurogenesis was studied by exposing cultured human NPCs in either maintaining or differentiating media to culture sups from purified $\mathrm{CD} 8{ }^{+} \mathrm{T}$-cells that had been activated with anti-CD3 and anti-CD28 antibodies. Cell proliferation was studied by monitoring BrdU incorporation in the NPCs by immunostaining. NPC differentiation was studied by immunostaining the cells cultured in the differentiating media for neuronal marker $\beta$-III-tubulin and astroglial marker GFAP. Sups from activated $\mathrm{CD}^{+}{ }^{+}$T-cells inhibited NPC proliferation (Fig. 1A) and neuronal differentiation (Fig. 1Bi) but increased astroglial differentiation (Fig. 1 Bii) significantly compared with control sups. To determine the role of $\mathrm{GrB}$ in activated T-cell-induced inhibition of NPC neurogenesis, we immunodepleted GrB from the activated T-cell sups by using a monoclonal antibody. Immunodepletion of GrB completely blocked activated T-cellinduced inhibition of NPC proliferation and neuronal differentiation, whereas depletion using a nonrelevant isotope control antibody showed no effect. GrB levels in the supernatants were $3.2+1.6 \mathrm{ng} / \mathrm{ml}$ (mean \pm SEM) or $\sim 100$ pM. To further confirm the role of GrB-induced inhibition on NPC neurogenesis, we used

at $4^{\circ} \mathrm{C}$ and then incubated in $30 \%$ sucrose solution. Serial coronal frozen sections of $40 \mu \mathrm{m}$ thickness were made from the hippocampus and DG. Every sixth section ( $240 \mu \mathrm{m}$ interval) was selected from each animal and processed for immunohistochemistry. Briefly, sections were permeabilized by incubation in $0.5 \%$ PBS-T for $20 \mathrm{~min}$, and then treated in $50 \%$ formamide $-2 \times$ standard saline citrate at $65^{\circ} \mathrm{C}$ for $2 \mathrm{~h}$, denatured in $2 \mathrm{~N}$ $\mathrm{HCl}$ at $37^{\circ} \mathrm{C}$ for $30 \mathrm{~min}$, and rinsed twice in $0.1 \mathrm{~m}$ sodium borate, $\mathrm{pH} 8.5$, at room temperature. Afterward, the sections were incubated overnight at $4^{\circ} \mathrm{C}$ with rat anti-BrdU (1:1000; Accurate), mouse anti-NeuN (1:500; Millipore), or mouse monoclonal anti-Kv1.3 (clone L23/27; 1:100; NeuroMab Facility, University of California, Davis, Davis, CA). Sections were washed in PBS-T and incubated with fluorescent conjugated secondary antibodies (Cy3 AffiniPure donkey anti-rat; 1:250; Jackson ImmunoResearch; anti-mouse Alexa Fluor 488, 1:400; Invitrogen) for $1 \mathrm{~h}$ at room temperature. Samples were also incubated in DAPI (1:5000; SigmaAldrich) for contrast nuclear staining. Images were acquired on a Zeiss LSM 510 META multiphoton confocal system using a multitrack configuration. All morphological analyses were performed on blind-coded slides. To analyze cell proliferation in the DG, BrdU-immunopositive cells were counted in the subgranular zone. The reference volume was determined by tracing the granule cell layer of the hippocampal DG.

Statistical analysis. For experiments that required immunostaining, the total number of cells and immunolabeled cells were counted in nine predetermined fields per coverslip or slide using a fluorescence microscope with a $20 \times$ objective. Three coverslips/slides were counted in each group. At least three independent experiments were performed. Means and SEM were calculated for each treatment group. Statistical analysis was performed using Prism, version 3.0. Differences were tested using either one-way ANOVA followed by Bonferroni's test for multiple comparisons or Student's $t$ test for two-group comparisons. Two-tailed values of $p<0.05$ were considered significant. recombinant $\mathrm{GrB}(1-4 \mathrm{nM})$ to treat NPC cultures. CytoQuantiBlue assay was used to determine the cell numbers after $24 \mathrm{~h}$ of treatment with GrB. GrB treatment decreased the NPC numbers in a concentration-dependent manner with a significant inhibition at $4 \mathrm{~nm}$ (Fig. 1C). Furthermore, immunostaining for active caspase- 3 showed that treatment with GrB at $10 \mathrm{~nm}$ for $24 \mathrm{~h}$ and $7 \mathrm{~d}$ only induced modest apoptosis in NPCs (Fig. $1 E, F$ ), whereas BrdU immunostaining showed that $\mathrm{GrB}$ at $4 \mathrm{~nm}$ significantly reduced BrdU incorporation (Fig. $1 D$ ), indicating its effect on the cell number was mainly through inhibition of cell proliferation. These observations indicate that activated $\mathrm{T}$-cells release soluble factors to inhibit NPC proliferation and neuron generation but increase astroglial differentiation. GrB is the main factor released from activated $\mathrm{T}$-cells that induces these effects.

\section{GrB-mediated inhibition of NPC proliferation is reversible by} Gi $\alpha /$ Go blockade by pertussis toxin

In a previous study, we found that GrB signals neuronal cells, at least in part, through a PTX-sensitive Gi $\alpha$-coupled receptor (Wang et al., 2006); hence we determined whether PTX could impact the GrB-induced inhibition of NPC proliferation observed herein. We treated NPCs with $100 \mathrm{ng} / \mathrm{ml}$ PTX $1 \mathrm{~h}$ before GrB (4 nM) treatment. As shown in Figure 2A, PTX treatment significantly attenuated GrB-mediated inhibition of NPC proliferation as determined by the amount of BrdU incorporation $(p<0.05)$, suggesting a role for $\mathrm{Gi} \alpha / \mathrm{Go}$-coupled receptors in the GrB-mediated inhibition of NPC proliferation. Furthermore, NPC cultures were treated with GrB (1-4 nM) for $15 \mathrm{~min}$ and 
intracellular cAMP level was determined by using an ELISA kit. As shown in Figure $2 B$, GrB treatment induced a significant decrease in the intracellular cAMP level in NPCs by $15 \mathrm{~min}$ in a dose-dependent manner $(p<0.05)$. This observation is consistent with the ability of GrB to act on a PTX-sensitive receptor on NPCs.

GrB-induced Kv1.3 expression in NPCs Kv1.3 channel has been previously implicated in neurogenesis (Liebau et al., 2006). We thus studied the effect of GrB on Kv1.3 expression in NPCs. The NPC cultures were treated with $\mathrm{GrB}$ (4 nM) for 1-3 h, and Kv1.3 expression was monitored by using real-time PCR. GrB treatment increased Kv1.3 expression in a time-dependent manner, which peaked at 2-3 h (Fig. 3A). To determine whether the increase in transcripts was also accompanied by a corresponding increase in protein, we immunostained NPCs for Kv1.3 after treatment with GrB. NPCs showed moderate staining in the untreated control cells, whereas GrB treatment for $24 \mathrm{~h}$ interestingly showed increased staining in a subpopulation of the NPCs (Fig. 3B). The GrB-induced Kv1.3 was also confirmed by Western blot analysis, which showed a dose-dependent increase in Kv1.3 protein (Fig. 3C).

\section{Blockade of Kv1.3 attenuated GrB-mediated inhibition of NPC neurogenesis}

To determine the effect of blocking Kv1.3 channel on GrB-mediated inhibition of NPC neurogenesis, we pretreated NPCs with a Kv1.3 blocker, MgTX (10 nM), 1 h before treatment with either GrB or sups from activated T-cells. Neurogenesis was quantified by immunostaining after $7 \mathrm{~d}$. It showed that MgTX significantly attenuated both, GrB (Fig. 4A) and activated T-cell sups-mediated (Fig. $4 B$ ) inhibition of NPC neurogenesis. To further confirm the role of Kv1.3 in inhibiting NPC neurogenesis, we delivered siRNA to the NPCs and first confirmed that the siRNA could specifically block Kv1.3 expression. No effect of negative control siRNA was seen. Next, the siRNAtreated cells were exposed to GrB, and NPC neurogenesis was quantified as described above. Similar to MgTX, siRNA to Kv1.3 also attenuated GrB-mediated inhibition of NPC neurogenesis (Fig. $4 C, D$ ).

\section{MgTX protected against GrB-mediated effects on NPC proliferation in vivo}

To determine the effect of GrB on NPC proliferation in vivo and the role of Kv1.3 activation in mediating these effects, rats were stereotaxically injected in the DG with GrB alone, MgTX and $\mathrm{GrB}$, or vehicle control. After $7 \mathrm{~d}$, the rats received BrdU, and the brains were processed for immunohistochemistry. GrB signif- icantly decreased BrdU-positive cells compared with control, whereas MgTX attenuated the decrease completely (Fig. $5 A, B)$. GrB treatment increased the expression of Kv1.3 on NPCs (Fig. 5C).

PTX pretreatment attenuated GrB-induced Kv1.3 expression To determine whether the effect of GrB on Gi $\alpha /$ Go-coupled receptors and Kv1.3 channel expression was linked or independent of one another, we pretreated NPC cultures with $100 \mathrm{ng} / \mathrm{ml}$ PTX $1 \mathrm{~h}$ before $\mathrm{GrB}$ ( $4 \mathrm{nM}$ ) treatment and monitored Kv1.3 expression after 3 h. PTX pretreatment significantly blocked Kv1.3 expression (Fig. 6), suggesting that the increased expression of the Kv1.3 channel is regulated by the stimulation of a Gi $\alpha / \mathrm{Go}$-coupled receptor by GrB. 


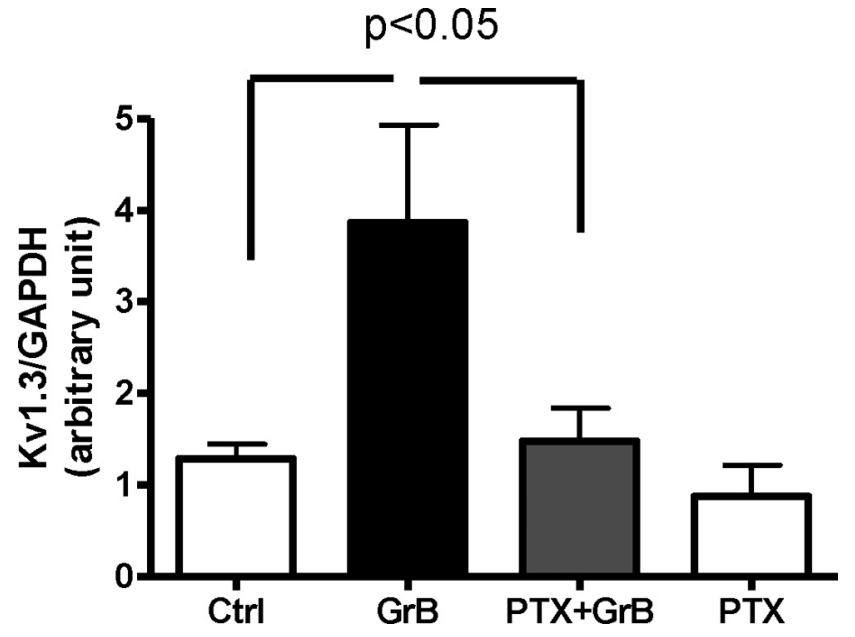

Figure 6. PTX attenuated GrB-induced Kv1.3 expression. NPC cultures were pretreated with PTX for $1 \mathrm{~h}$ before GrB treatment. The cells were lysed $3 \mathrm{~h}$ after GrB treatment. Kv1.3 mRNA was detected using real-time PCR. The results were expressed as folds compared with control. Data were from three independent experiments. Error bars indicate SEM.

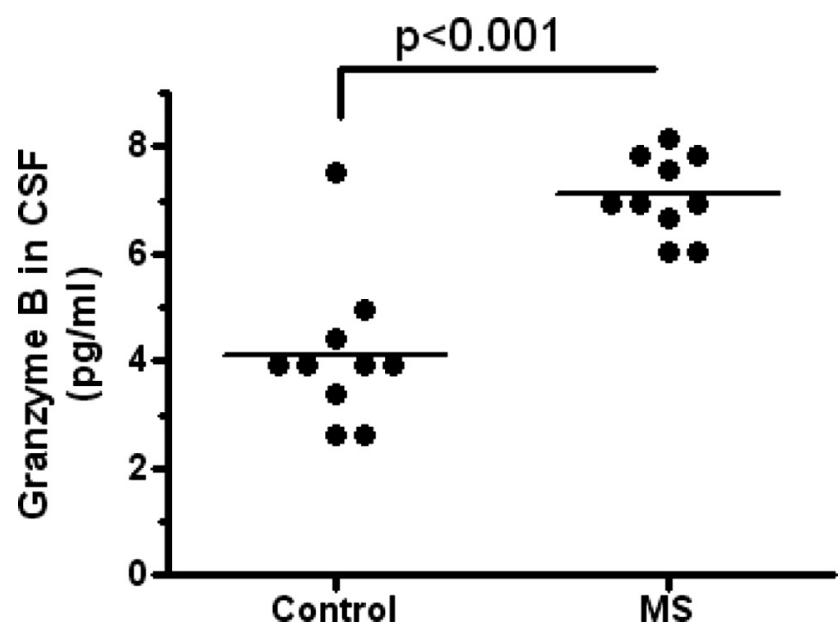

Figure 7. CSF levels of GrB. Levels of GrB were measured in CSF of patients with multiple sclerosis (MS) $(n=10)$ and headaches (controls; $n=10)$ by ELISA. Significantly elevated levels were found in patients with MS. The bars represent mean values.

\section{GrB levels in CSF of patients with multiple sclerosis}

To determine the pathological relevance of GrB-mediated effects, we measured GrB levels in CSF of patients with multiple sclerosis (mean $\pm \mathrm{SE}, 7.1 \pm 0.2 \mathrm{pg} / \mathrm{ml}$ ) and found that they had significantly elevated levels compared with patients with headaches (mean $\pm \mathrm{SE}, 4.1 \pm 0.4 \mathrm{pg} / \mathrm{ml}$ ) (Fig. 7).

\section{Discussion}

In neuroinflammatory diseases such as multiple sclerosis, T-cells play a key pathogenic role. Although their role in mediating damage to myelin has been extensively studied, it has only recently been realized that activated T-cells can directly injure neurons as well. For example, the extent of axonal damage is directly related to the numbers of infiltrated T-cells in multiple sclerosis plaques (Kuhlmann et al., 2002). In vitro studies have also shown that activated T-cells can induce direct neuronal damage, through both cell contact-dependent (Giuliani et al., 2003) and -independent pathways (Wang et al., 2006). In the present study, we observed that patients with multiple sclerosis had higher levels of GrB compared with controls in their CSF. To investigate the neuropathological role of $\mathrm{GrB}$, we activated $\mathrm{CD} 8^{+}$T-cells and found that $\mathrm{GrB}$ released extracellularly by these cells decreased NPC proliferation and neurogenesis. The mechanism involves activation of a G-protein-coupled receptor, decrease in intracellular cAMP, and activation of the Kv1.3 channel. We show that Kv1.3 may be an important therapeutic target.

The discovery that NPCs are present in the adult brain and that these cells are capable of forming neurons and glial cells has raised hopes that neurorestorative therapy for a wide variety of neurological disorders may be within reach $\mathrm{McDonald}$ and Wojtowicz, 2005; Goya et al., 2007; Hsu et al., 2007; Duncan et al., 2008). One approach has been to implant the NPCs or stem cells into the nervous system. This has been successfully used in experimental systems of acute injury models, in which the local environment promotes the differentiation of the stem cells or NPCs to form neurons and even establish the meaningful connections with target cells (Joannides et al., 2007; Niranjan et al., 2007; Yan et al., 2007). Human fetal brain cells have also been implanted in patients with Parkinson's disease, however with limited success (Goya et al., 2007). This type of approach in neurodegenerative and neuroinflammatory diseases poses unique challenges. It remains unknown whether the microenvironment of glial cell activation or T-cell infiltration is conducive or hostile to the NPCs. It is possible that the brain atrophy associated with these diseases may be in part attributable to the failure of the endogenous NPCs to replace the lost neurons. Hence understanding the effects of the microenvironment on the NPCs would be important for the function of the endogenous NPCs as well as conditions in which these cells may be implanted in the nervous system. Previous studies have shown that, under physiological conditions, T-cells may promote neurogenesis in the adult brain via interactions with microglia and release of growth factors such as insulin growth factor (Ziv and Schwartz, 2008a,b). In pathological conditions such as multiple sclerosis, which is the best studied of all neuroinflammatory diseases, however, the T-cells are activated and inflammatory infiltrate contains cytotoxic T-cells (Goverman et al., 2005; Friese et al., 2008). These cells are often present in the subventricular zones in which the NPCs are commonly found (Nait-Oumesmar et al., 2007; Wang et al., 2008). We thus determined whether activated $\mathrm{CD} 8{ }^{+} \mathrm{T}$-cells could impact the function of NPCs. Since NPCs have the ability to proliferate and renew themselves, we maintained the human NPCs in culture conditions that promote proliferation of these cells without differentiation and found that the sups from the activated CD ${ }^{+}$ T-cells impaired the ability of these cells to proliferate but did not affect their survival. Similarly, when we cultured the NPCs in differentiating media, the sups inhibited their differentiation to neurons. These findings are consistent with observations that patients with multiple sclerosis when treated with natalizumab, which blocks T-cell entry into the brain, had decreased brain atrophy (Miller et al., 2007).

One of the features that differentiate the activated $\mathrm{CD} 8{ }^{+}$ $\mathrm{T}$-cells from other T-cells is the presence of cytotoxic granules, which contains several enzymatic proteins. The contents of these granules are released on activation. Of these proteins, GrB is known to trigger apoptotic pathways, once it enters the cells (Trapani, 2001); however, it may also cause neuronal injury through interaction with cell surface receptors. Through a series of experiments in which we exposed the NPCs to culture supernatants from which GrB had been removed and treated NPCs directly with recombinant $\mathrm{GrB}$, it was clear that $\mathrm{GrB}$ alone was sufficient to impair NPC function. Both culture supernatants and recombinant $\mathrm{GrB}$ activated similar pathways, since their effects 
could be blocked by similar pharmacological agents as discussed below. The effect of GrB on NPC proliferation was further confirmed by in vivo studies, in which injection of GrB into the dentate gyrus resulted in deceased proliferation of the NPCs. Interestingly, GrB impaired the ability of NPCs to differentiate to neurons but not to astrocytes. The amount of recombinant GrB needed to affect NPC function was $\sim 10$ - to 40 -fold greater than that required when produced by T-cells. This is likely because the process of purification and storage of recombinant proteins often leads to some degradation. Furthermore, recombinant GrB was produced in Escherichia coli and hence would lack posttranslational modifications, which would be present when released from human lymphocytes and could alter its potency.

Although subsets of CD4 ${ }^{+}$T-cells can also express GrB (van Leeuwen et al., 2004), the release of GrB is more dominant in $\mathrm{CD}^{+}{ }^{+} \mathrm{T}$-cells. $\mathrm{GrB}$ is a serine protease that can induce apoptosis by caspase activation after crossing the plasma membrane of target cells, usually with the help with perforin (Trapani, 2001). Interestingly, by using recombinant GrB to treat NPC cultures, we confirmed that GrB treatment significantly inhibited NPC proliferation and neuronal differentiation independent of perforin. The effects of GrB were PTX sensitive, suggesting the stimulation of the Gi $\alpha$-coupled receptors (Tepe and Liggett, 2000). Gi $\alpha$-coupled receptors are known to regulate adenylyl cyclase, which in turn regulates cAMP levels. cAMP and cAMPdependent protein kinase (PKA) play a pivotal role in regulating neurogenesis. Increase in intracellular cAMP and subsequent activation of PKA pathway have been reported to enhance the proliferation of retinal ganglion cells but inhibit their differentiation by regulating the cell cycle exit (Masai et al., 2005). Activation of the cAMP signaling pathway and its transcriptional factor, cAMP response element-binding protein (CREB), play critical roles in neurite growth and neuronal differentiation induced by neurotrophic factors in a variety of conditions (Chen et al., 2005; Pan et al., 2005; Chu et al., 2006). We found that GrB decreased cAMP levels in NPCs in a dose-responsive manner. This effect was mediated via interactions of $\mathrm{GrB}$ with $\mathrm{Gi} \alpha$-coupled receptors. This suggests that CAMP may be the critical second messenger in mediating GrB-induced inhibition in NSC neurogenesis. Thus, GrB may play a role in regulating neurogenesis by regulating CAMPCREB signaling and subsequent transcription of CREB-target genes essential for neuronal differentiation.

$\mathrm{K}^{+}$is the most dominant ion in the cytosol and plays a critical role in maintaining the cellular ion homeostasis and normal cell volume (Lang et al., 1998). As cell shrinkage is a hallmark of apoptosis, it is not surprising that enhancement of the plasma membrane permeability to $\mathrm{K}^{+}$ions has been associated with an early response to apoptotic stimuli in a number of cell types including neurons (Yu et al., 1999). Additionally, outward delayed rectifier $\mathrm{K}^{+}$current is present in differentiating NPCs and the amplitude of the current can be significantly diminished by inhibiting caspases, indicating that activation of the delayed rectifier $\mathrm{K}^{+}$current in differentiating stem cells is related to apoptosis (Hribar et al., 2004). In contrast to the outward delayed rectifier $\mathrm{K}^{+}$current, an inward rectifying potassium channel was reported to be important in maintaining cytokine-induced primitive progenitor cell growth and differentiation (Shirihai et al., 1996). Kv1.3 is a Shaker-type delayed rectifier $\mathrm{K}^{+}$channel found in human T-lymphocytes and microglia (Storey et al., 2003). It has been shown that Kv1.3 expressed both on the cell surface and mitochondrial membrane and its function may be related to mitochondrial dysfunction (Bock et al., 2002; Szabò et al., 2005). Blockade of Kv1.3 in T-cells results in T-cell depolarization, in- hibition of T-cell activation, and the attenuation of immune responses in vivo. Also, blockade of Kv1.3 in microglia results in attenuated microglial activation and subsequent prevention of neurotoxicity (Fordyce et al., 2005). As both T-cells and microglia play important roles in the pathogenesis of multiple sclerosis, it is likely that Kv1.3 could be used as a target in treatment of multiple sclerosis. Indeed, treatment with several Kv1.3 antagonists has been shown to be effective in ameliorating experimental allergic encephalomyelitis (Beeton et al., 2001, 2006). However, $\mathrm{Kv1} 3$ also plays a role in modulating oligodendrocyte progenitor cell (OPC) proliferation and blockade in Kv1.3 inhibits OPC proliferation (Chittajallu et al., 2002). Thus, it is of interest to carefully delineate the effect of Kv1.3 on NPC function. We found that, whereas there was a small basal level expression of Kv1.3 in NPCs, treatment with GrB significantly increased the expression of Kv1.3 transcripts and protein. Furthermore, pretreatment with MgTX, a Kv1.3 blocker, and siRNA to Kv1.3 enhanced neurogenesis in both control and GrB-treated NPCs, suggesting that Kv1.3 plays an important role in regulating NPC function. Kv1.3 thus represents a novel target that could be exploited to prevent toxicity in NPCs from activated T-cells and at the same time enhance their ability to proliferate and differentiate into neurons.

In conclusion, we showed that activated T-cells release GrB, which inhibits neurogenesis via membrane-mediated interactions. GrB causes stimulation of $\mathrm{Gi} \alpha$ receptors, leading to a decrease in cAMP levels and increased expression of Kv1.3 channel on NPCs. Importantly, we also found that blocking Kv1.3 pharmacologically leads to increased differentiation of the NPCs into neurons, which clearly suggests that Kv1.3 may be a key molecule for pharmacological intervention in stem cell therapy. These observations may have important implications for T-cell-mediated neurodegenerative diseases.

\section{References}

Arvidsson A, Collin T, Kirik D, Kokaia Z, Lindvall O (2002) Neuronal replacement from endogenous precursors in the adult brain after stroke. Nat Med 8:963-970.

Beeton C, Barbaria J, Giraud P, Devaux J, Benoliel AM, Gola M, Sabatier JM, Bernard D, Crest M, Béraud E (2001) Selective blocking of voltage-gated $\mathrm{K}^{+}$channels improves experimental autoimmune encephalomyelitis and inhibits T cell activation. J Immunol 166:936-944.

Beeton C, Wulff H, Standifer NE, Azam P, Mullen KM, Pennington MW, Kolski-Andreaco A, Wei E, Grino A, Counts DR, Wang PH, LeeHealey CJ, S Andrews B, Sankaranarayanan A, Homerick D, Roeck WW, Tehranzadeh J, Stanhope KL, Zimin P, Havel PJ, et al. (2006) Kv1.3 channels are a therapeutic target for T cell-mediated autoimmune diseases. Proc Natl Acad Sci U S A 103:17414-17419.

Bock J, Szabó I, Jekle A, Gulbins E (2002) Actinomycin D-induced apoptosis involves the potassium channel Kv1.3. Biochem Biophys Res Commun 295:526-531.

Chard DT, Griffin CM, Rashid W, Davies GR, Altmann DR, Kapoor R, Barker GJ, Thompson AJ, Miller DH (2004) Progressive grey matter atrophy in clinically early relapsing-remitting multiple sclerosis. Mult Scler 10:387-391.

Chen S, Ji M, Paris M, Hullinger RL, Andrisani OM (2005) The cAMP pathway regulates both transcription and activity of the paired homeobox transcription factor Phox2a required for development of neural crestderived and central nervous system-derived catecholaminergic neurons. J Biol Chem 280:41025-41036.

Chittajallu R, Chen Y, Wang H, Yuan X, Ghiani CA, Heckman T, McBain CJ, Gallo V (2002) Regulation of Kv1 subunit expression in oligodendrocyte progenitor cells and their role in $G_{1} / S$ phase progression of the cell cycle. Proc Natl Acad Sci U S A 99:2350-2355.

Chu MS, Chang CF, Yang CC, Bau YC, Ho LL, Hung SC (2006) Signalling pathway in the induction of neurite outgrowth in human mesenchymal stem cells. Cell Signal 18:519-530.

Duncan ID, Goldman S, Macklin WB, Rao M, Weiner LP, Reingold SC 
(2008) Stem cell therapy in multiple sclerosis: promise and controversy. Mult Scler 14:541-546.

Fordyce CB, Jagasia R, Zhu X, Schlichter LC (2005) Microglia Kv1.3 channels contribute to their ability to kill neurons. J Neurosci 25:7139-7149.

Friese MA, Fugger L (2005) Autoreactive CD8 ${ }^{+} \mathrm{T}$ cells in multiple sclerosis: a new target for therapy? Brain 128:1747-1763.

Friese MA, Jakobsen KB, Friis L, Etzensperger R, Craner MJ, McMahon RM, Jensen LT, Huygelen V, Jones EY, Bell JI, Fugger L (2008) Opposing effects of HLA class I molecules in tuning autoreactive $\mathrm{CD} 8{ }^{+} \mathrm{T}$ cells in multiple sclerosis. Nat Med 14:1227-1235.

Furby J, Hayton T, Anderson V, Altmann D, Brenner R, Chataway J, Hughes R, Smith K, Miller D, Kapoor R (2008) Magnetic resonance imaging measures of brain and spinal cord atrophy correlate with clinical impairment in secondary progressive multiple sclerosis. Mult Scler 14:10681075.

Giuliani F, Goodyer CG, Antel JP, Yong VW (2003) Vulnerability of human neurons to T cell-mediated cytotoxicity. J Immunol 171:368-379.

Goverman J, Perchellet A, Huseby ES (2005) The role of CD8 ${ }^{+} \mathrm{T}$ cells in multiple sclerosis and its animal models. Curr Drug Targets 4:239-245.

Goya RL, Kuan WL, Barker RA (2007) The future of cell therapies in the treatment of Parkinson's disease. Expert Opin Biol Ther 7:1487-1498.

Hayashi J, Takagi Y, Fukuda H, Imazato T, Nishimura M, Fujimoto M, Takahashi J, Hashimoto N, Nozaki K (2006) Primate embryonic stem cellderived neuronal progenitors transplanted into ischemic brain. J Cereb Blood Flow Metab 26:906-914.

Hribar M, Bloc A, Medilanski J, Nüsch L, Eder-Colli L (2004) Voltage-gated $\mathrm{K}^{+}$current: a marker for apoptosis in differentiating neuronal progenitor cells? Eur J Neurosci 20:635-648.

Hsu YC, Lee DC, Chiu IM (2007) Neural stem cells, neural progenitors, and neurotrophic factors. Cell Transplant 16:133-150.

Hu L, Pennington M, Jiang Q, Whartenby KA, Calabresi PA (2007) Characterization of the functional properties of the voltage-gated potassium channel Kv1.3 in human CD4 ${ }^{+}$T lymphocytes. J Immunol 179:45634570 .

Ikeda R, Kurokawa MS, Chiba S, Yoshikawa H, Ide M, Tadokoro M, Nito S, Nakatsuji N, Kondoh Y, Nagata K, Hashimoto T, Suzuki N (2005) Transplantation of neural cells derived from retinoic acid-treated cynomolgus monkey embryonic stem cells successfully improved motor function of hemiplegic mice with experimental brain injury. Neurobiol Dis 20:38-48.

Joannides AJ, Webber DJ, Raineteau O, Kelly C, Irvine KA, Watts C, Rosser AE, Kemp PJ, Blakemore WF, Compston A, Caldwell MA, Allen ND, Chandran S (2007) Environmental signals regulate lineage choice and temporal maturation of neural stem cells from human embryonic stem cells. Brain 130:1263-1275.

Kuhlmann T, Lingfeld G, Bitsch A, Schuchardt J, Brück W (2002) Acute axonal damage in multiple sclerosis is most extensive in early disease stages and decreases over time. Brain 125:2202-2212.

Lang F, Busch GL, Ritter M, Völkl H, Waldegger S, Gulbins E, Häussinger D (1998) Functional significance of cell volume regulatory mechanisms. Physiol Rev 78:247-306.

Liebau S, Pröpper C, Böckers T, Lehmann-Horn F, Storch A, Grissmer S, Wittekindt $\mathrm{OH}$ (2006) Selective blockage of Kv1.3 and Kv3.1 channels increases neural progenitor cell proliferation. J Neurochem 99:426-437.

Masai I, Yamaguchi M, Tonou-Fujimori N, Komori A, Okamoto H (2005) The hedgehog-PKA pathway regulates two distinct steps of the differentiation of retinal ganglion cells: the cell-cycle exit of retinoblasts and their neuronal maturation. Development 132:1539-1553.

Matsushita T, Matsuoka T, Ishizu T, Kikuchi H, Osoegawa M, Kawano Y, Mihara F, Ohyagi Y, Kira J (2008) Anterior periventricular linear lesions in optic-spinal multiple sclerosis: a combined neuroimaging and neuropathological study. Mult Scler 14:343-353.

McDonald HY, Wojtowicz JM (2005) Dynamics of neurogenesis in the dentate gyrus of adult rats. Neurosci Lett 385:70-75.

Miller DH, Soon D, Fernando KT, MacManus DG, Barker GJ, Yousry TA, Fisher E, O'Connor PW, Phillips JT, Polman CH, Kappos L, Hutchinson M, Havrdova E, Lublin FD, Giovannoni G, Wajgt A, Rudick R, Lynn F, Panzara MA, Sandrock AW, et al. (2007) MRI outcomes in a placebocontrolled trial of natalizumab in relapsing MS. Neurology 68:13901401.
Nait-Oumesmar B, Picard-Riera N, Kerninon C, Decker L, Seilhean D, Höglinger GU, Hirsch EC, Reynolds R, Baron-Van Evercooren A (2007) Activation of the subventricular zone in multiple sclerosis: evidence for early glial progenitors. Proc Natl Acad Sci U S A 104:4694-4699.

Niranjan A, Fellows W, Stauffer W, Burton EA, Hong CS, Lunsford LD, Kondziolka D, Glorioso JC, Gobbel GT (2007) Survival of transplanted neural progenitor cells enhanced by brain irradiation. J Neurosurg 107:383-391.

Pan Y, Chen X, Wang S, Yang S, Bai X, Chi X, Li K, Liu B, Li L (2005) In vitro neuronal differentiation of cultured human embryonic germ cells. Biochem Biophys Res Commun 327:548-556.

Pluchino S, Zanotti L, Rossi B, Brambilla E, Ottoboni L, Salani G, Martinello M, Cattalini A, Bergami A, Furlan R, Comi G, Constantin G, Martino G (2005) Neurosphere-derived multipotent precursors promote neuroprotection by an immunomodulatory mechanism. Nature 436:266-271.

Schwab N, Bien CG, Waschbisch A, Becker A, Vince GH, Dornmair K, Wiendl H (2009) $\mathrm{CD}^{+}{ }^{+}$T-cell clones dominate brain infiltrates in Rasmussen encephalitis and persist in the periphery. Brain 132:1236-1246.

Shichita T, Sugiyama Y, Ooboshi H, Sugimori H, Nakagawa R, Takada I, Iwaki T, Okada Y, Iida M, Cua DJ, Iwakura Y, Yoshimura A (2009) Pivotal role of cerebral interleukin-17-producing gammadeltaT cells in the delayed phase of ischemic brain injury. Nat Med 15:946-950.

Shirihai O, Merchav S, Attali B, Dagan D (1996) $\mathrm{K}^{+}$channel antisense oligodeoxynucleotides inhibit cytokine-induced expansion of human hemopoietic progenitors. Pflugers Arch 431:632-638.

Storey NM, Gómez-Angelats M, Bortner CD, Armstrong DL, Cidlowski JA (2003) Stimulation of Kv1.3 potassium channels by death receptors during apoptosis in Jurkat T lymphocytes. J Biol Chem 278:33319-33326.

Szabò I, Bock J, Jekle A, Soddemann M, Adams C, Lang F, Zoratti M, Gulbins E (2005) A novel potassium channel in lymphocyte mitochondria. J Biol Chem 280:12790-12798.

Tepe NM, Liggett SB (2000) Functional receptor coupling to Gi is a mechanism of agonist-promoted desensitization of the beta2-adrenergic receptor. J Recept Signal Transduct Res 20:75-85.

Trapani JA (2001) Granzymes: a family of lymphocyte granule serine proteases. Genome Biol 2:REVIEWS3014.

Uccelli A, Zappia E, Benvenuto F, Frassoni F, Mancardi G (2006) Stem cells in inflammatory demyelinating disorders: a dual role for immunosuppression and neuroprotection. Expert Opin Biol Ther 6:17-22.

van Leeuwen EM, Remmerswaal EB, Vossen MT, Rowshani AT, Wertheimvan Dillen PM, van Lier RA, ten Berge IJ (2004) Emergence of a $\mathrm{CD} 4{ }^{+} \mathrm{CD} 28^{-}$granzyme $\mathrm{B}^{+}$, cytomegalovirus-specific $\mathrm{T}$ cell subset after recovery of primary cytomegalovirus infection. J Immunol 173:18341841.

Venkataramana A, Pardo CA, McArthur JC, Kerr DA, Irani DN, Griffin JW, Burger P, Reich DS, Calabresi PA, Nath A (2006) Immune reconstitution inflammatory syndrome in the CNS of HIV-infected patients. Neurology 67:383-388.

Wang T, Allie R, Conant K, Haughey N, Turchan-Chelowo J, Hahn K, Rosen A, Steiner J, Keswani S, Jones M, Calabresi PA, Nath A (2006) Granzyme $B$ mediates neurotoxicity through a G-protein-coupled receptor. FASEB J 20:1209-1211.

Wang Y, Imitola J, Rasmussen S, O’Connor KC, Khoury SJ (2008) Paradoxical dysregulation of the neural stem cell pathway sonic hedgehog-Gli1 in autoimmune encephalomyelitis and multiple sclerosis. Ann Neurol 64:417-427.

Yan J, Xu L, Welsh AM, Hatfield G, Hazel T, Johe K, Koliatsos VE (2007) Extensive neuronal differentiation of human neural stem cell grafts in adult rat spinal cord. PLoS Med 4:e39.

Yu SP, Yeh CH, Gottron F, Wang X, Grabb MC, Choi DW (1999) Role of the outward delayed rectifier $\mathrm{K}^{+}$current in ceramide-induced caspase activation and apoptosis in cultured cortical neurons. J Neurochem 73:933-941.

Ziv Y, Schwartz M (2008a) Immune-based regulation of adult neurogenesis: implications for learning and memory. Brain Behav Immun 22:167-176.

Ziv Y, Schwartz M (2008b) Orchestrating brain-cell renewal: the role of immune cells in adult neurogenesis in health and disease. Trends Mol Med 14:471-478. 